Von Menschen und Maschinen 


\title{
Von Menschen \\ UND MASCHINEN
}

\author{
Industriekultur \\ in Baden-Württemberg
}

\author{
Von Wilfried Setzler \\ in Zusammenarbeit mit Kerstin Laschewski, \\ Benigna Schönhagen und Sibylle Setzler
}

Verlag J. B. Metzler

Stuttgart · Weimar 
Die Drucklegung dieses Buches wurde durch die freundliche Unterstützung der Baden-Württembergischen Bank AG, Stuttgart, ermöglicht.

Die Deutsche Bibliothek - CIP-Einheitsaufnahme

Von Menschen und Maschinen: Industriekultur in Baden-

Württemberg / von Wilfried Setzler u. a. - Stuttgart ; Weimar :

Metzler, 1998

ISBN 978-3-476-01588-4

ISBN 978-3-476-03730-5 (eBook)

DOI 10.1007/978-3-476-03730-5

Dieses Werk einschließlich aller seiner Teile ist urheberrechtlich geschützt. Jede Verwertung außerhalb der engen Grenzen des Urheberrechtsgesetzes ist ohne Zustimmung des Verlages unzulässig und strafbar. Das gilt insbesondere für Vervielfältigungen, Übersetzungen, Mikroverfilmungen und die Einspeicherung und Verarbeitung in elektronischen Systemen.

(C) 1998 Springer-Verlag GmbH Deutschland

Ursprünglich erschienen bei J. B. Metzlersche Verlagsbuchhandlung und Carl Ernst

Poeschel Verlag GmbH in Stuttgart 1998 


\section{Inhaltsverzeichnis}

Einleitung 1

Die industrielle Revolution in Baden-Württemberg 13

Von der Dampfmaschine zum High-Tech 15

Die Anfänge der Industrialisierung 19

Staatliche Wirtschaftspolitik, gesetzliche Rahmenbedingungen 26

Verbesserung der Infrastruktur 36

Der Durchbruch 45

Die zweite Phase der industriellen Revolution 61

Die weiße Kohle gleicht Standortnachteile aus 62

Robert Bosch und der Magnetzünder 64

Die Motorisierung 66

Alte Branchen wachsen, neue entstehen, der deutsche Südwesten wird Spitze 68

Die Industrialisierung verändert das Leben radikal: Im Südwesten anders als anderswo? 70

Der erste Weltkrieg und die Krisen in der Weimarer Republik 77

In der Zeit nationalsozialistischer Herrschaft 80

Das Ende des Zweiten Weltkriegs, der Wiederaufbau und die dritte industrielle Revolution 85

Vom Morgenthau- zum Marshallplan 85

Das Wirtschaftswunder 86

High-Tech, die dritte industrielle Revolution? 91

Das Ende der Fabrik und die virtuelle Wirklichkeit 95

Infrastruktur: Die Eisenbahn als Träger der Kultur 97

Die Verkehrswege: Straßen, Kanäle und Eisenbahn 99

Die Eisenbahnkultur 103

Lokomotive und Wagen 108

Bahnhöfe, Bahnwärterhäuschen 110

Tunnels und Brücken 119 
Der Unternehmer 123

(Sibylle Setzler)

Persönlichkeiten 125

Das soziale Engagement der Unternehmer 143

Förderung der "Corporate Identity», betriebsinterne Aktivitäten 155

Kulturelles Mäzenatentum und Sponsoring 161

Repräsentation durch Kunstförderung 165

Das Unternehmen 173

(Benigna Schönhagen)

Die Idylle der rauchenden Schornsteine - Fabrikanlage als Kunstobjekt 175

Prachtvolle Zweckbauten - Fabrikanlagen als Aufgabe der Architektur 179

Fabrikantenvillen und Repräsentativbauten 204

Arbeiterwohnsiedlungen 209

Das Produkt 219

(Kerstin Laschewski)

Die Entwicklung des Produktdesign 221

Vom Warenzeichen zum Markenartikel 236

Wirtschaftswerbung zwischen Kunst und Kommerz 243

Die Industrie in Malerei und Grafik 261

(Sibylle Setzler)

Die Industrielandschaft 263

Die Arbeitswelt 269

Wegmarken der Industrialisierung: Eisenbahn, Elektrizität, Autos, Luftschiffahrt 276

Technikangst und Technikbegeisterung nach 1945282

Anhang 289

Anmerkungen 290

Literaturverzeichnis 292

Bildnachweis 297 